\title{
Structural assessment of concrete bullfighting arenas
}

Received: 29 th October, 2005

\begin{abstract}
Jorge de Brito
graduated in civil engineering and received his masters and doctorate degrees at IST-Technical University of Lisbon, Portugal, where he is an associate professor. He is a member of IABSE, $\mathrm{FIB}, \mathrm{CIB}$ and IABMAS, as well as several reputed national engineering societies. He is a member of several national committees under CEN, as well as the following working groups: $\mathrm{CIB}$ W80/RILEM 100 -TSL - Service Life Prediction of Building Materials and Components; CIB W86 Building Pathology; and $\mathrm{CIB} \mathrm{TG}_{39}$ - Deconstruction. His research work deals with deterioration, rehabilitation and management of concrete structures. He co-authored the Handbook of Concrete Bridge Management, published by ASCE Press in 2004.
\end{abstract}

\section{Fernando A. Branco}

is full professor of civil engineering at IST-Technical University of Lisbon, Portugal. He is Chairman of the Technical Committee of IABSE and a member of the ACI Committee No. 343 on 'Evaluation of Concrete Bridges'. He is also a member of FIB, CIB and IABMAS. His primary research interests deal with the behaviour and pathology of bridges and other public works. He has co-authored the Handbook of Concrete Bridge Management (ASCE Press, 2004) and over 200 scientific papers.
Abstract
Bullfighting arenas comprise a very interesting example of infrastructures that are exposed to harsh environmental conditions and, for economic reasons, they frequently do not benefit from periodic maintenance. A set of Portuguese bullfighting arenas with a concrete structure was subjected to a structural assessment campaign to evaluate their safety under their public live loads. These structures are described both in terms of their shape and functioning and the construction materials used and added along their service life. The main pathologies detected are presented, with the most frequent structural problems concerning cracking/ spalling of the concrete elements caused by reinforcement corrosion and water-related problems. The main durability connected problems detected were water infiltration (due to the lack of a waterproofing membrane), various problems involving the external coatings and corrosion in the concrete elements. Nonstructural problems concerned mostly deficiencies in the drainage system. A summary of the rehabilitation recommendations is provided, with a strong emphasis on coatings. The in situ measurements (mostly in terms of sclerometer readings and carbonation depths) are presented as well as the main conclusions drawn from their results. A benchmarking of concrete structures exposed to harsh atmospheric conditions is presented, comprising bridges, deck parkings and bullfighting arenas. It is concluded that maintenance is the keystone to durability.

Instituto Superior Técnico Departamento de Eng. Civil e Arquitectura Av. Rovisco Pais 1049-001 Lisboa, Portugal Tel: +351218419709 Fax: +35118497650 E-mail: jb@civil.ist.utl.pt 


\section{Keywords:}

concrete bullfighting arenas, structural assessment, carbonation, pathology, rehabilitation measures

\section{Bull fighting arenas: Their specific problems}

\section{INTRODUCTION}

Bullfighting arenas are very special infrastructures. As with stadia, they are subjected to harsh environmental conditions but, due to the declining number of aficionados, are used very sporadically and therefore generate very low income, which is insufficient for proper maintenance. (In Portugal, on average, only between three to seven bullfights are held per year in each arena.) In most cases, bullfighting arenas are owned by public entities (such as parish juntas) and welfare organisations that manage them in a mostly amateurish fashion totally lacking in current maintenance operations, such as keeping the drainage systems operational or making sure the decks are watertight. Furthermore, the construction of these structures usually resulted from volunteer and amateurish efforts and financing, with far from perfect design solutions, almost always with an exposed concrete superstructure and benches in which the concrete strength (and therefore its resistance to the penetration of aggressive agents such as carbon dioxide and chlorides) is very low and the compaction often deficient.

The Portuguese authority responsible for public shows, namely those held in bullfighting arenas, asked for a structural assessment of the arenas that apparently presented the most serious problems in terms of safety and/or durability. Three main reasons explained this decision. First, due to the facts mentioned above, even some of the relatively new arenas showed evident signs of structural and nonstructural degradation. Secondly, Portugal is a seismic country and seismic codes have evolved dramatically in the last decades, imposing stricter safety rules that some of the arenas did not comply with when they were originally designed. Thirdly, bullfights sometimes bring several thousand spectators to the arenas, which represents a very high public risk, especially in terms of the safety of the benches.

This paper presents the main results of the structural assessment of a set of seven Portuguese concrete bullfighting arenas inspected over a oneyear period. It complements another study (de Brito and Branco, 2006) concerning pre-structural concrete bullfighting arenas, mostly with stone and/or brick masonry walls, arches and vaults, which presented a different set of problems. The work consisted mostly of a detailed visual inspection of the structures and a diagnosis of the causes of the main structural/construction, durability-related and nonstructural anomalies found, as well as a set of recommendations as to how to solve the problems detected and eliminate, wherever possible, their primary causes. The description and statistical survey of these anomalies, causes and rehabilitation measures are preceded by a description of the arenas inspected in terms of structural materials and typology. A study of the evolution of the carbonation process within the structural elements is also presented. The paper closes with a set of conclusions concerning the 
pathology of this very special type of structure and the maintenance procedures they must be subjected to.

This being the third of a set of papers concerning the pathology found in concrete infrastructures subjected to harsh environmental conditions (the others being expressway bridges in an urban area (de Brito et al., 2005a) and deck parkings (de Brito et al., 2005b)), some comparisons are made and general conclusions drawn between them.

\section{DESCRIPTION OF THE BULLFIGHTING ARENAS INSPECTED}

\section{The Portuguese arenas}

There are 71 bullfighting arenas in Portugal (Figure 1), of which 16 have not been active in the last few years. They are concentrated in the south/central interior regions near Spain (such as in Alentejo) or where the wild bulls are bred (Ribatejo). A number of these arenas have been subject to a qualitative structural assessment according to the priorities of and availability of financing from the licensing authorities.

The locations of the concrete bullfighting arenas inspected (Figure 1) are listed below, as well as the year in which they were built (in some of the cases, the original structure had been replaced by one made of concrete

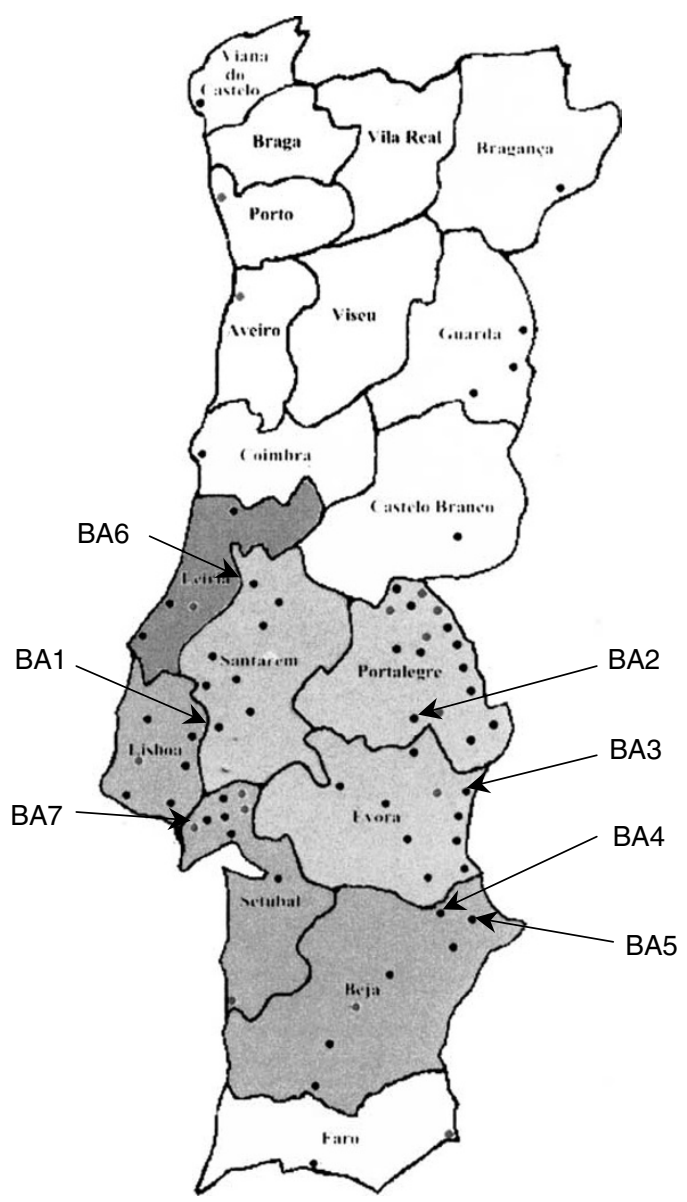

Figure 1: Distribution of the bullfighting arenas throughout Portugal and location of the arenas inspected 


\section{Description of the structures}

the date of which is included in parentheses) and their spectator capacity (the average ages of the arenas and the concrete structures were 45 and 35 years, respectively).

- Salvaterra de Magos (Figure 2, left), 1920 (1943/1948), 3,992 (BA1);

- Alter do Chão (Figure 2, right), 1918 (1963 and 1978), 2,294 (BA2);

- Elvas, 1984, 1,894 (BA3);

- Póvoa de S. Miguel (Figure 3, left), 1982, 1,000 (BA4);

- Amareleja (Figure 3, right), 1985/1991, 1,000 (BA5);

- Abiúl (Figure 4, left), 1972, 6,000 (BA6);

- Montijo (Figure 4, right), 1957, 6,281 (BA7).

From a structural point of view, these buildings were more or less of the same type, even though the oldest ones still incorporated old materials and structural solutions from their original design and showed a series of
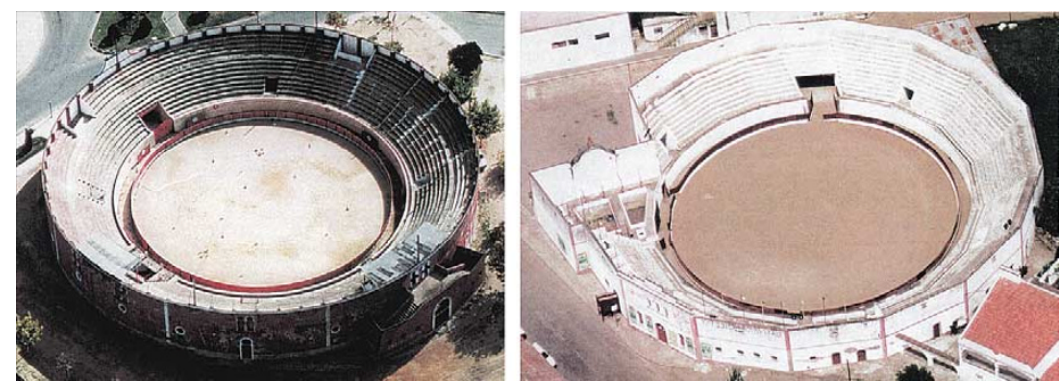

Figure 2: Bullfighting arenas of Salvaterra de Magos (left) and Alter do Chão (right)
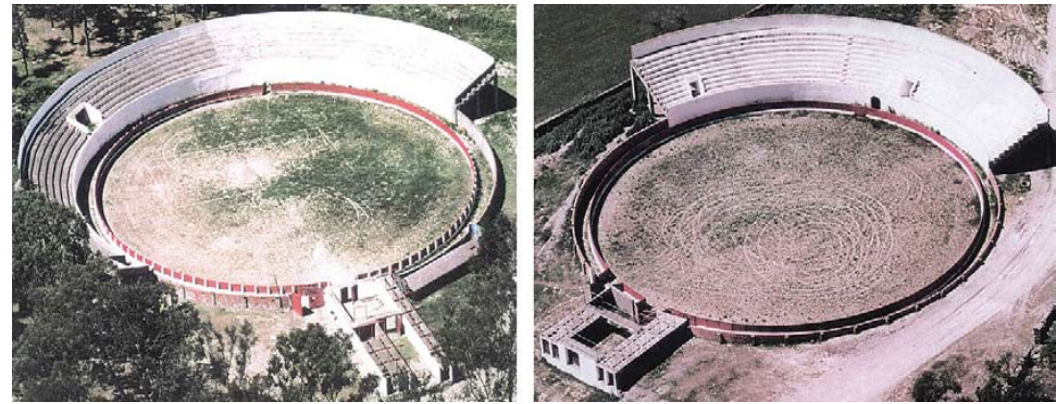

Figure 3: Bullfighting arenas of Póvoa de S. Miguel (left) and Amareleja (right)
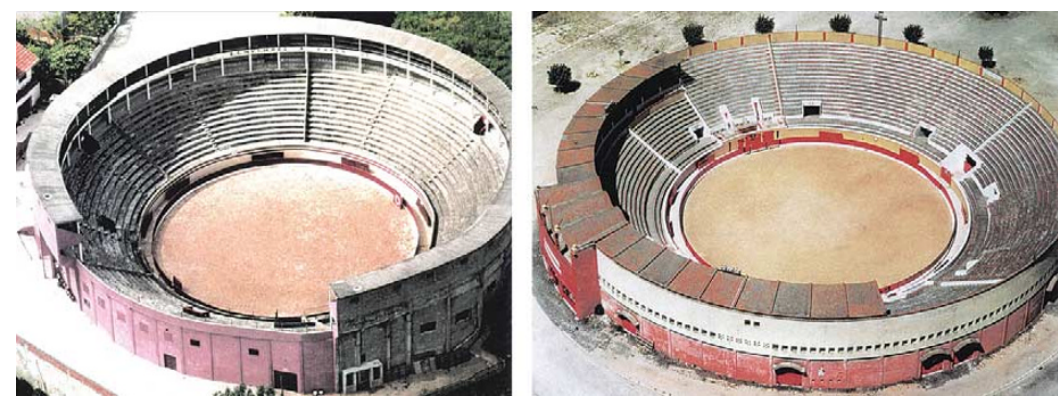

Figure 4: Bullfighting arenas of Abiúl (left) and Montijo (right) 

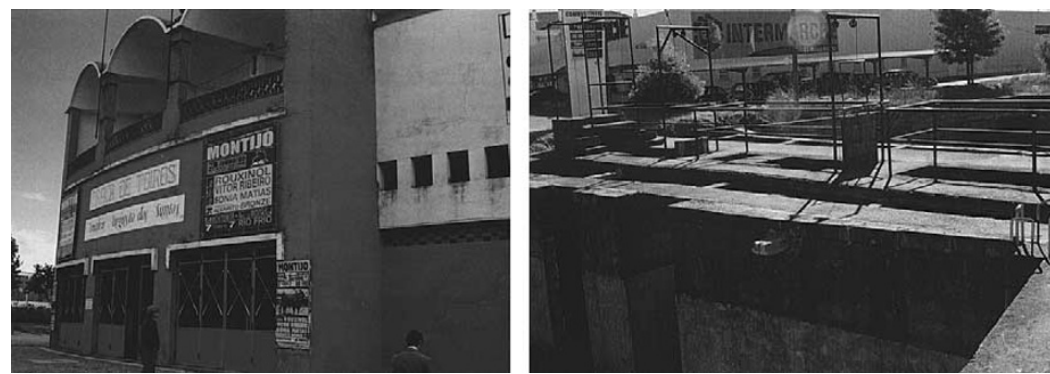

Figure 5: Main entrance in Montijo (left) and bull pen in Elvas (right)

Geometry of the arenas minor and major rehabilitation interventions, to cope with new needs and the natural degradation of the materials, incorporating different structural and nonstructural materials according to different ages and trends, quite often within a very limited budget.

In terms of their shape in plans (Figures 2-4), the arenas inspected were perfectly circular in six cases and multi-polygonal in one case, even though some of them had projecting parts that corresponded either to the main entrance (Figure 5, left), exterior staircases or the bull pen (Figure 5, right). Several facilities (reception hall, infirmary, offices, sleeping quarters, chapel, stores, stables, ticket offices, restrooms, bull pen, etc) also existed within the arenas. Usually, these facilities were within nonstructural, hollow-brick, cement-based, rendered and painted partition walls. As for structural type, the arenas, all in reinforced and/or prestressed concrete, can be grouped in the following way:

- BA1 had two concentric exterior rings, both from the original structure and made of hollow-brick masonry (Figure 6, right), and two intermediate rings of brick masonry columns and arches (Figure 6, left) all connected by concrete radial trusses (Figure 6, right);

- BA2 had two concentric exterior rings, connected by radial walls with arches (Figure 7, left) all from the original structure and made of irregular stone and hollow-brick masonry;

- BA3, BA4, BA5 and BA6 (BA4 and BA5 in only half the perimeter) had two-span concrete radial frames (Figure 7, right) with hardly any transversal bracing;

- BA7 had four-span (two cantilevered) concrete radial frames without transversal bracing.
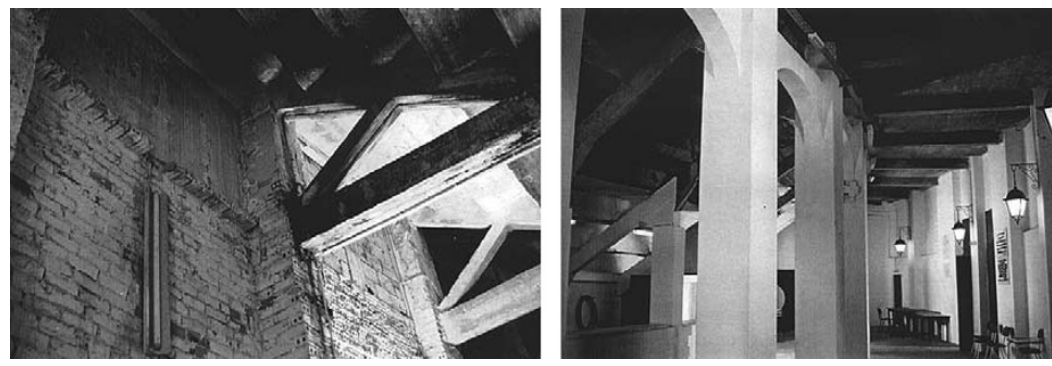

Figure 6: Structure of the Salvaterra de Magos arena showing intermediate brick columns and arches (left) and brick masonry walls and concrete radial trusses (right) 

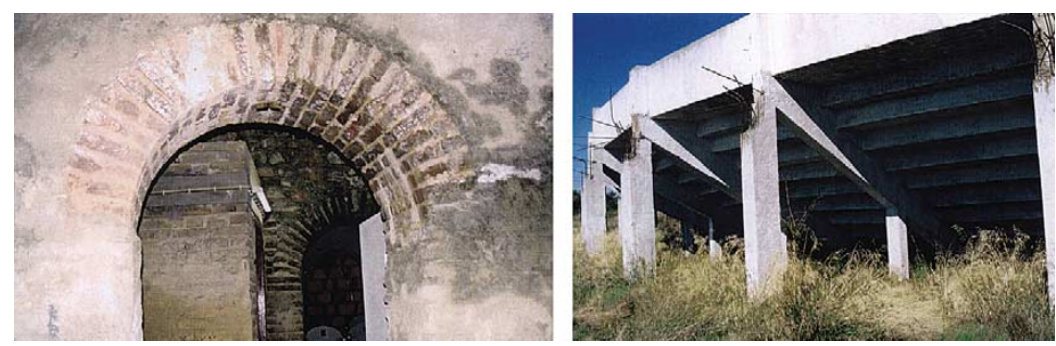

Figure 7: Masonry radial walls and arches in Alter do Chão (left) and unbraced concrete radial frames in Elvas (right)

\section{Materials used}

The structural materials used were fundamentally reinforced concrete in all the frames/trusses (BA1) (in every arena even if only as an exception in BA2) and precast, prestressed joists in the benches. In the older arenas (BA1 and BA2), hollow structural brick and a mix of irregular stone and hollow-brick masonry were used in the columns (BA1), walls and arches. The coating of these masonry elements consisted of limestone or cementitious renders, water-based paint and/or a lime coat, or nothing at all. As for the concrete elements, most of them had no coating. The localised exceptions were water-based painted (BA1, BA2 and BA3), had a cementitious coating and a water-based paint (BA4 and BA5), used render and paint, applied progressively over the last ten years (BA6) or had used just paint (BA7).

Pavements were either slabs made of reinforced concrete or precast, prestressed joists (with ceramic hollow-vault bricks) in the case of the older arenas built some decades after the initial construction. Coatings of these pavements were either nonexistent or made of cement-based mortar. In the older arenas, the original pavements over the bull pen (made of timber or solid ceramic small vaults supported by I-shaped metallic beams) had been removed and replaced with very thin reinforced concrete slabs (BA1) or very recently built flat slabs (BA2). The staircases in every arena were made of reinforced concrete. Parapets were metallic and/or made of rendered hollow bricks in every arena.

In arena BA1, a small covered area was built some decades after the initial construction to house spectator cabins (Figure 8, left). This structure was supported by metallic columns and the outer structural ring, and the roof was made of asbestos-cement corrugated sheets supported by metallic trusses. In arena BA6, the original cabins, covering half the perimeter, were extended about 25 years ago using the same structural type (Figure 8, right): two-storey-high columns made of concrete-filled asbestos-cement tubes in the front ring and one-storey-high reinforced concrete columns in the back ring, supporting reinforced concrete bracing beams and precast, prestressed concrete joist (with ceramic hollow-vault bricks) slabs. Finally, in arena BA7, the cabins were part of the original reinforced concrete structure and comprised slabs and shells (Figure 5, left) directly supported by two rings of columns.

The seats, which in the oldest arenas originally had been made from timber, had been replaced by reinforced concrete cast in situ (BA1 Figure 9, left — and BA2) or precast, prestressed joists and hollow bricks 

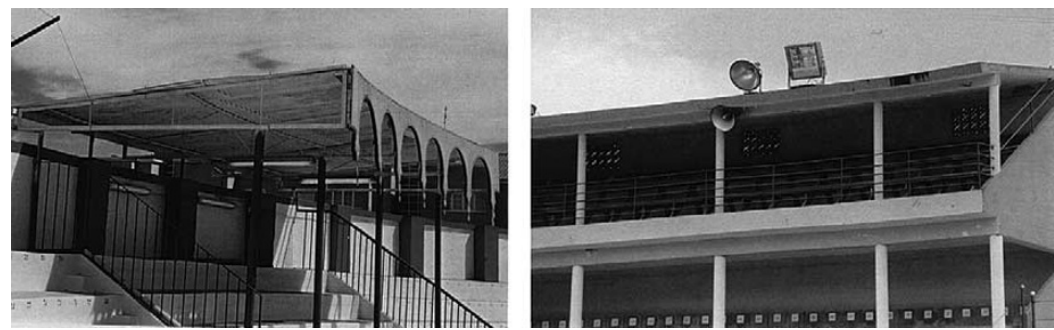

Figure 8: Cabin structures in Salvaterra de Magos (left) and in Abiúl (right)
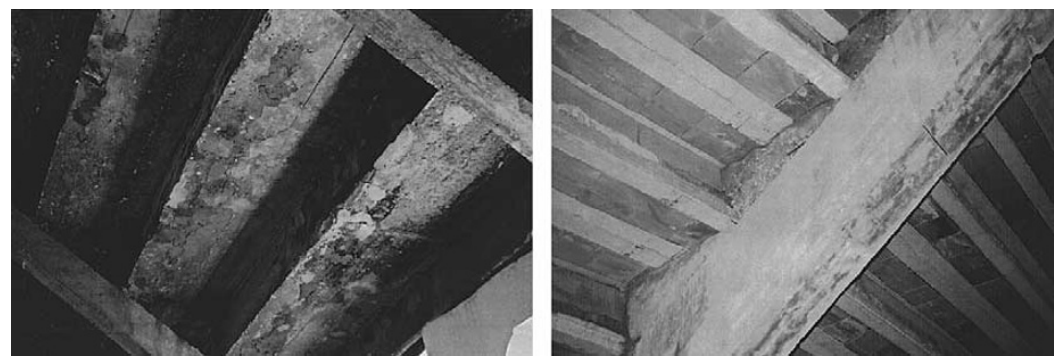

Figure 9: Cast in situ reinforced concrete seats in Salvaterra de Magos (left), showing patches of faulty repairs, and seats made of prestressed concrete joists and hollow bricks in Elvas (right)

(BA2). In the younger arenas, the original design of the seats featured the same two solutions (Figure 9, right). In arena BA6, there was an old timber structure that supported the actual seats (Figure 10, left). In every case, the seats were simply supported by the radial structural elements (frames, trusses or walls). Their upper surfacing consisted of a cementbased mortar, sometimes with a coating of water-based paint or lime, but never a proper waterproofing system (in one of the arenas ceramic tiles were used to partially top the seats). The lower surfacing, if any (Figure 9, left and right), consisted of a cement-based render either painted or lime-coated or just the paint/lime.

Some structures presented interesting/unusual features such as:

\section{Unusual features}

- BA1's intermediate ring columns were made of structural brick

(Figure 6, right) even though they were quite slender;

- BA3 was never built according to the original plans (about half the benches were in the radial direction of what was planned) and, at the
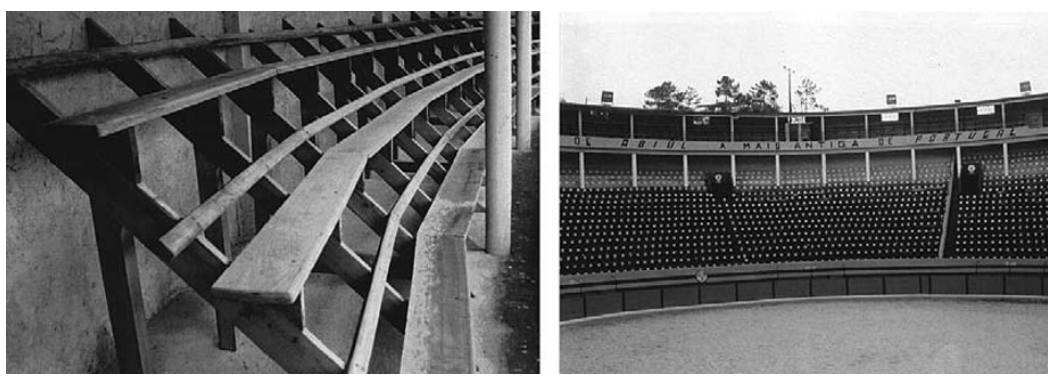

Figure 10: Timber seat structures in Abiúl (left) and the heiress of the oldest Portuguese bullfighting arena also in Abiúl (right) 
time of the assessment, it was planned to be totally refurbished into a multi-use pavilion by the municipality;

- BA4 was built intermittently according to fund-raising campaigns and more than one contractor was involved, thus resulting in construction that was highly scattered in terms of quality and geometric precision;

- both BA4 and BA5 had benches only covering half the perimeter due to lack of funding (Figure 3, left and right);

- BA6 had replaced a timber structure from the 1930s supposed to have been built on the site of the first bullfighting arena in Portugal built in the 16th century (Figure 10, right).

\section{RESULTS OF THE STRUCTURAL ASSESSMENT}

\section{General remarks}

Some of the early 20th-century bullfighting arenas (such as BA1 and BA2) had undergone refurbishments that consisted mostly of the replacement of the timber seats with concrete elements. Other interventions had led to the inclusion or restructuring of internal substructures also generally in concrete. In the more modern arenas, the structure was made mostly of concrete but, due to the various factors mentioned above, these infrastructures had undergone serious and precocious degradation.

Given their age and/or level of degradation, the structures of the arenas would have great difficulties in complying with the necessary structural safety codes, namely the Portuguese codes of 1983 . In this context, the structural assessments described here aimed essentially at qualitatively evaluating the safety of the structures and, in particular, the spectator seats under live loads. The following principles were taken into account:

- without resorting to complex analyses, it is agreed that the structural safety concerning the occurrence of a very strong seism cannot be ascertained; however, the probability of the simultaneous occurrence of a seism and a bullfight (on average only six occur per year in each arena leading to an almost nil quasi-permanence value of the live load) is so extremely low that it can be disregarded;

- the safety of the spectator seats concerning the design value of live loads had been tested frequently as most bullfights filled the arenas; in other words, actual load tests had been performed without any accidents in the past and only specific calculations for each situation could demonstrate unequivocally the structural safety as defined by the codes; other public entertainment facilities decades old have not been subject to such an analysis.

In this situation, the loss of safety of the seats could only result from their physical deterioration over time or from an accident that might have occurred in the meantime. Therefore, the practical goal of the structural assessments was to detect structural degradation or accident-prone situations that might lead to hypothetical short- or medium-term unsafe conditions of the seats under the live load of the spectators. 


\section{Analysis of the defects' frequency}

The campaign of structural assessment of the bullfighting arenas was carried out in order to detect anomalies of two main types: those associated with problems of mechanical behaviour and those resulting from the degradation of the materials over time. The pathologies found were then divided into three groups: structural or construction pathologies, durability anomalies and nonstructural pathologies. An analysis of the frequency and variety of the pathologies found is presented next for each group.

\section{Structural or construction pathologies}

During the structural assessment of the bullfighting arenas, various structural anomalies were detected, which were problematic from an aesthetic and functional point of view and hinted at structural safety problems. Table 1 presents the frequency and variety of these pathologies.

By analysing Table 1, one can conclude that the most frequent anomaly in the concrete bullfighting arenas that were inspected, occurring in every case, was infiltration of various origins (1) (Figure 11, left), usually simultaneous with a durability anomaly, eg water dribbling with signs of rust and salts. Water is the main source of problems in infrastructures such as these, which are extremely exposed to aggressive environmental elements. The lack of watertightness of the benches, and the fact that they tended to crack, added to the lack of a waterproofing membrane in benches and roofings (a durability anomaly commented on below), were the main reasons for this anomaly that was itself a cause of other problems, both structural and durability-related.

Radial cracking of the benches at the supports (2) (Figure 11, right) and porous concrete (3) (Figure 12, left) occurred in every arena except one in each case (86 per cent) and probably only because recent maintenance works managed to hide the corresponding symptoms. The first anomaly was caused by the seats simply being supported by the radial walls or frames and their deformation cracking the upper coating. This would not be a serious problem except for the fact that these cracks were the main gateway for the water to infiltrate the structure. As for the porous concrete,

Table I: Structural pathologies detected in the structural assessment of the bullfighting arenas

\begin{tabular}{lc}
\hline Description & Frequency (\%) \\
\hline I Infiltration of various origins & 100 \\
2 Radial cracking of the benches at the supports & 86 \\
3 Porous concrete & 86 \\
4 Cracking/spalling of concrete columns & 57 \\
5 Cracking/spalling of concrete slabs and/or beams & 57 \\
6 Deterioration resulting from previous defective repairs & 57 \\
7 Cracking of nonstructural walls & 57 \\
8 Open expansion joints & 57 \\
9 Deteriorated hollow bricks in slabs/benches & 57 \\
I0 Cracking/spalling of concrete seats & 43 \\
II Lack of verticality of structural elements & 29 \\
I2 Loss of material of elements from walls/arches/vaults & 29 \\
I3 Cracking in masonry walls/arches/columns & 14 \\
I4 Degraded timber elements & 14 \\
I5 Over-deformation of benches & 14 \\
\hline
\end{tabular}



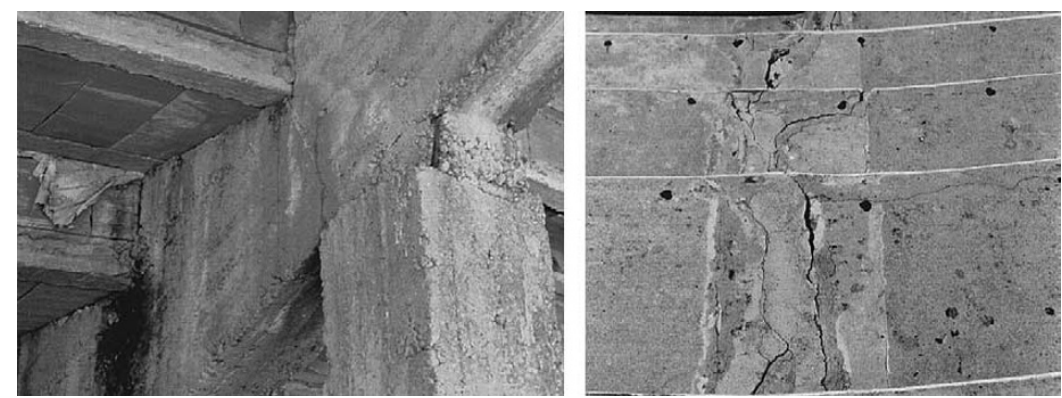

Figure 11: Infiltration of various origins in Amareleja (left) and radial cracking of the benches at the supports in Salvaterra de Magos (right)
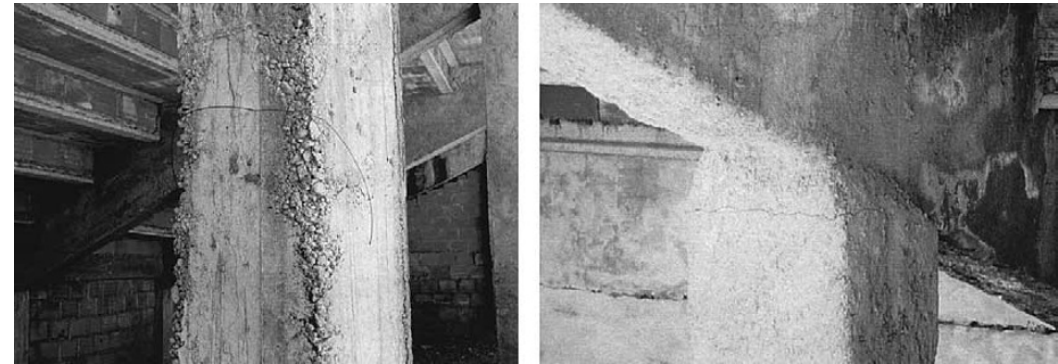

Figure 12: Porous concrete (left) and cracking of concrete columns (right), both in Amareleja

it was a trade mark of low-standard construction, as was certainly the case with these under-funded infrastructures built by the contractor with the lowest bid and in at least two of the cases subjected to intermittent funding at the construction stage. Again, the anomaly had further and harsher consequences, in terms of reinforcement corrosion and cracking/spalling of concrete structural elements.

Indeed, cracking and/or spalling of concrete elements occurred in columns (4) (Figure 12, right), beams and slabs (5) (Figure 14) and seats (10) (Figure 15, left) in 57, 57 and 43 per cent of the cases, respectively. In most cases, this was associated with reinforcement corrosion (a durability pathology that occurred in every arena that is commented on below) but there were other causes: settlement of the shoring, faulty demoulding and defective cold joints (Figure 12, right). In one of the arenas, the settlement of the exterior wall and the shrinkage/expansion movements of the concrete cabins' roofing had caused cracking and spalling of the top of various columns (Figures 13 and 14). The frequency presented for the seats was deceiving as the anomaly occurred in every case in which the concrete was cast in situ and, in one of them, the spalling was so widespread and deep (Figure 15, left) that a temporary closure of the arena was proposed to allow it to be repaired.

Other uncorrelated anomalies in more than half ( 57 per cent) of the arenas were as follows:

\section{Miscellaneous anomalies}

- deterioration resulting from previous defective repairs (6) (Figure 15, right), either because corrosion processes had proceeded and caused the 

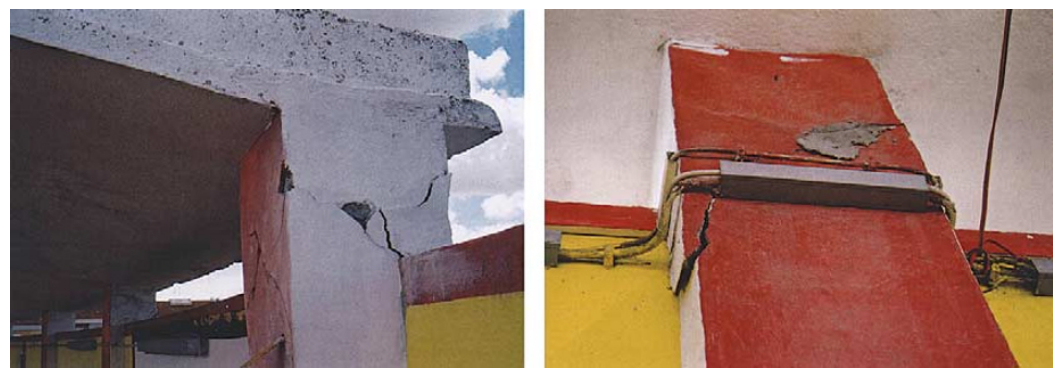

Figure 13: Columns dangerously cracked and spalled near their connection with the roofing in Montijo
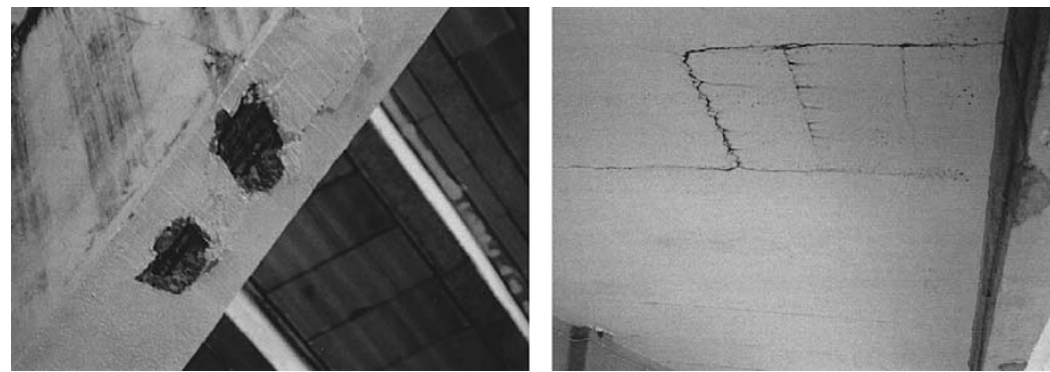

Figure 14: Spalling of concrete beam in Montijo (left) and cracking of concrete slab in Abiúl (right)
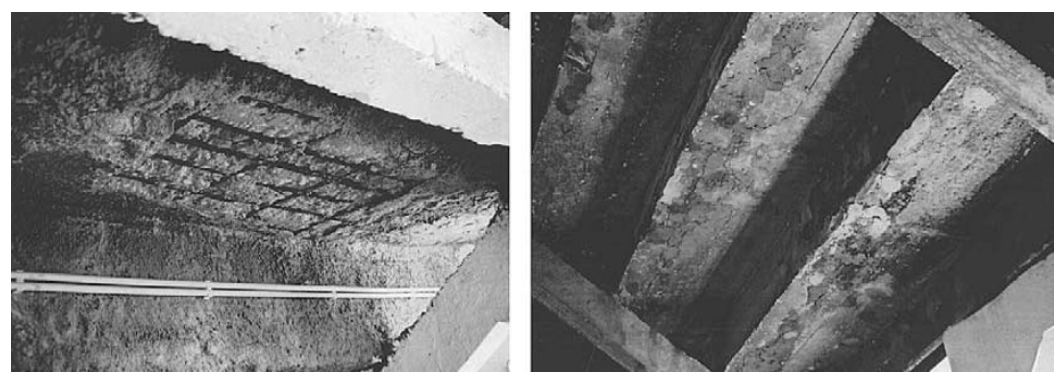

Figure 15: Spalling of concrete seats (left) and deterioration resulting from previous defective repairs (right), both in Salvaterra de Magos

spalling of the repair patches or because hollow bricks from the seats were filled with mortar, thus increasing their weight;

- cracking of nonstructural walls (7) (Figure 16), caused by foundations settlement (of the structure or the walls themselves) or internal movements due to thermal gradients or changes in humidity that usually led to cracking in the boundary between different materials;

- open expansion joints (8) (Figure 17, left), mostly due to the total lack of maintenance and also deficient drainage of the roofing; it must be stressed that this anomaly was detected in every case where there were expansion joints and it led to serious problems in terms of infiltration and its consequences;

- deteriorated hollow bricks in slabs/benches (9) (Figure 17, right); in all the most recently-built arenas inspected, the seats were made of 

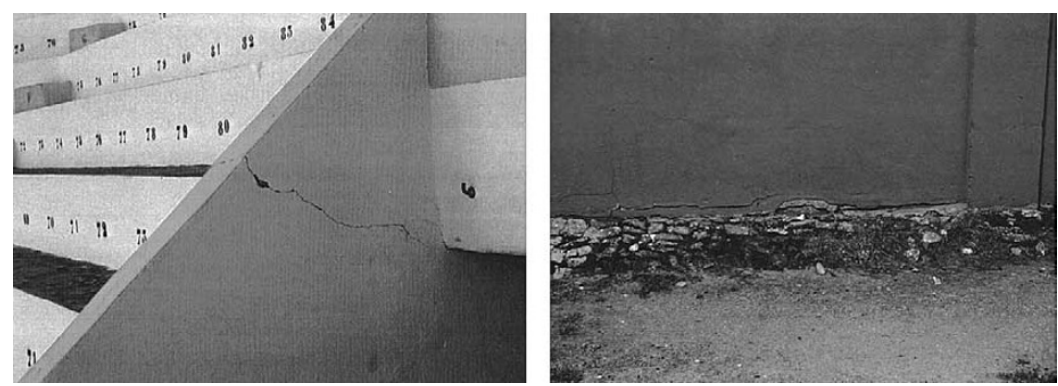

Figure 16: Cracking of non-structural walls in Alter do Chão (left) and, due to foundations settlement, in Montijo (right)
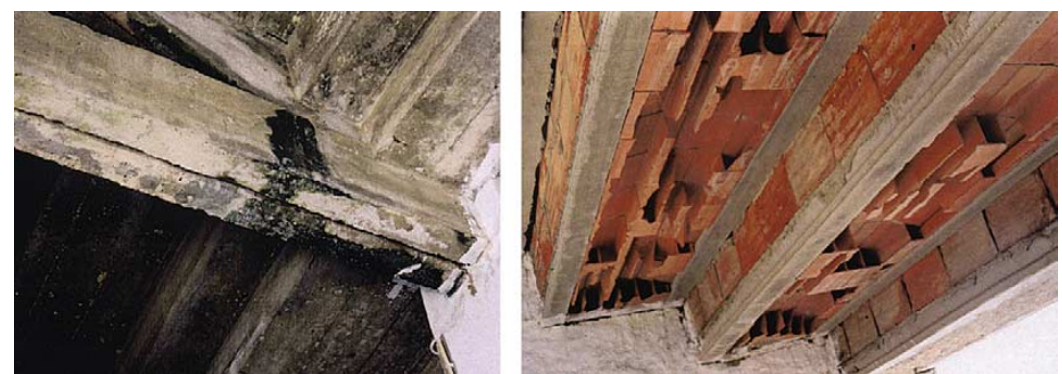

Figure 17: Open expansion joints in Salvaterra de Magos (left) and deteriorated hollow bricks in benches in Amareleja (right)

prestressed joist beams and hollow bricks and in most cases there was no undercoating; due to vandalism or the natural brittleness of this ceramic material, many bricks were fractured.

Other less frequent anomalies (occurring only once or twice) were:

\section{Less frequent anomalies}

- lack of verticality of structural elements (11) (Figure 18, left), another clear sign of very poor workmanship during the construction stage that, coincidentally, occurred in both arenas that were built in stages, using more than one contractor and based on unreliable funding;

- loss of material from elements of walls/arches/vaults (12) (Figure 18, right) and cracking in masonry walls/arches/columns (13) (Figure 19, right), both from the two oldest arenas (BA1 and BA2); these are typical problems of brick/stone masonry structures not within
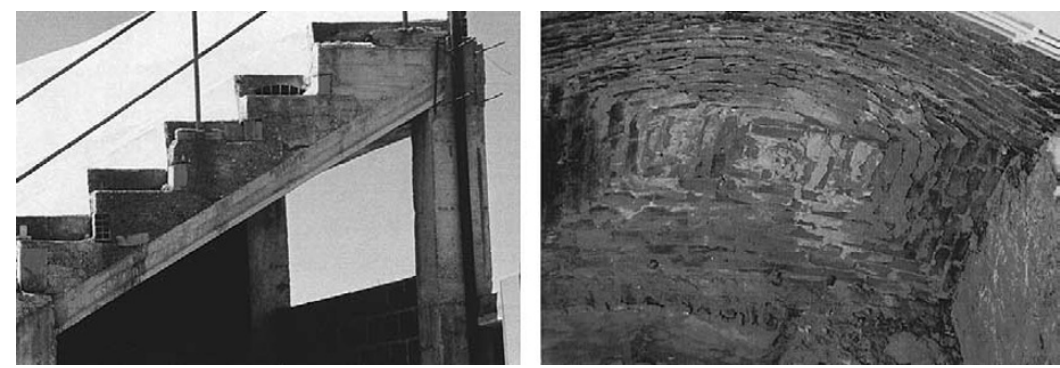

Figure 18: Lack of verticality of structural elements in Póvoa de S. Miguel (left) and loss of material from elements of vaults in Alter do Chão (right) 

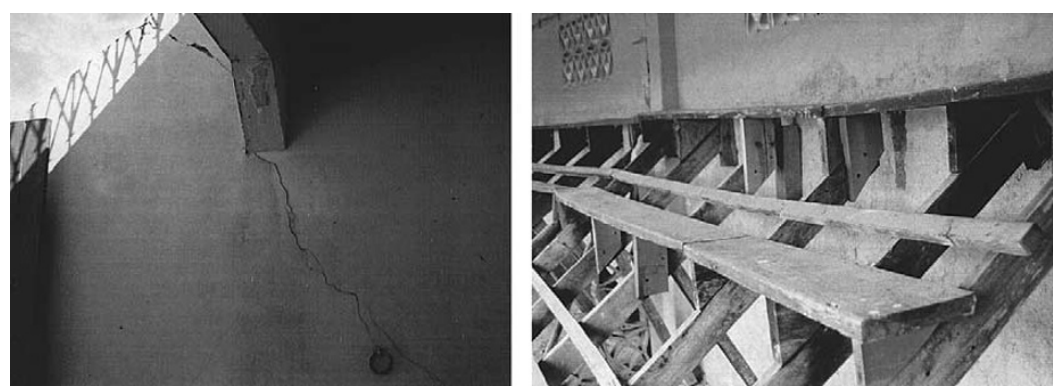

Figure 19: Cracking in masonry walls in Salvaterra de Magos (left) and degraded timber elements in Abiúl (right)

the scope of the present paper but analysed thoroughly in de Brito and Branco (2006);

- degraded timber elements (14) and over-deformation of benches (15)

(Figure 19, right), a problem that occurred only once, in an arena where there were still timber seats that had suffered deterioration caused by humidity/water, loss of effectiveness of the connections and creep of the wood; concrete seats showed no problems concerning deformation.

\section{Analysis of the defects' frequency}

\section{Durability pathologies}

During the structural assessment of the bullfighting arenas, several durability pathologies were found related mostly to reinforcement corrosion and the lack of a waterproofing system of the benches/roofing. The statistical survey of the frequency and variety of these pathologies is presented in Table 2.

By analysing Table 2, it can be seen that three pathologies were detected in every arena inspected: lack of waterproofing membrane in benches/roofing (1) (Figure 20, left), water dribbling with signs of rust and salts (2) (Figure 20, right) and reinforcement corrosion (3) (Figure 21, left). These are simultaneously anomalies and causes of anomalies and are presented in the sequence in which they tended to occur: the lack of waterproofing (and also faulty expansion joints) led to water dribbling (mostly under the radial supports of the seats where they cracked and under the expansion joints) that led to reinforcement corrosion (especially

Table 2: Durability-related pathologies detected in the structural assessment of the bullfighting arenas

Description
I Lack of waterproofing membrane in benches/roofing
2 Water dribbling with signs of rust and salts
3 Reinforcement corrosion
4 Cracking of external coatings
5 Humidity/peeling in external coatings
6 Condensation/funguses

Frequency (\%) 

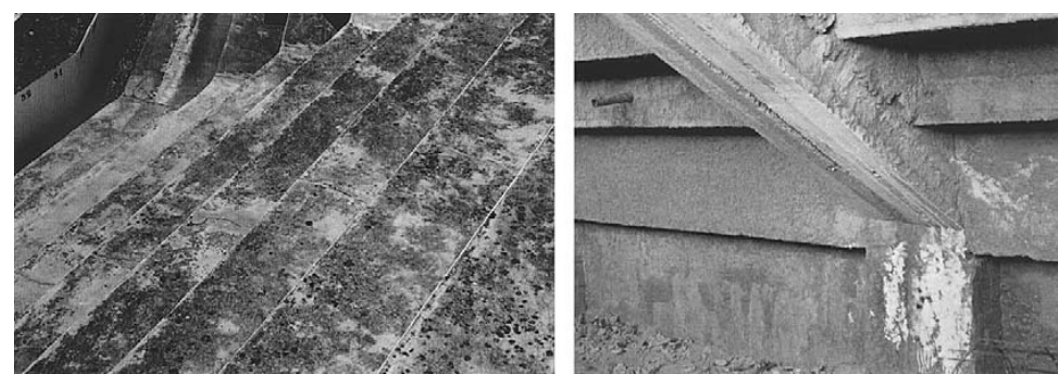

Figure 20: Lack of waterproofing membrane in benches in Alter do Chão (left) and water dribbling with signs of rust and salts in Póvoa de S. Miguel (right)
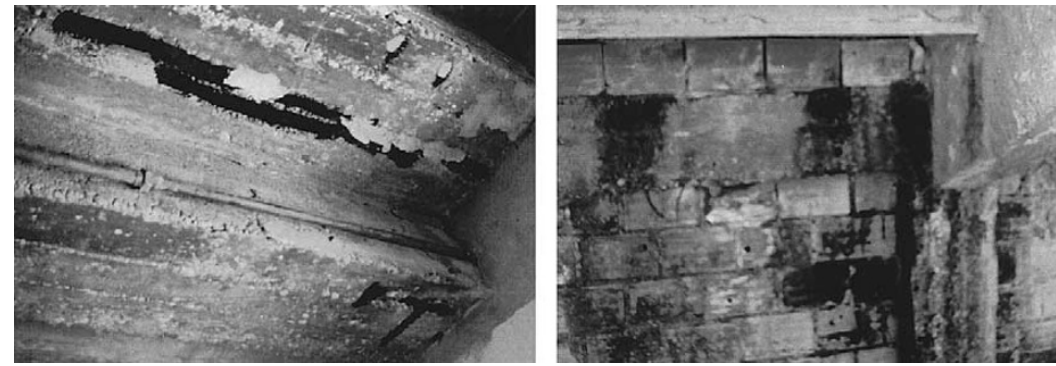

Figure 21: Reinforcement corrosion in Salvaterra de Magos (left) and funguses in Amareleja (right)

where the concrete was porous) and further on to cracking and spalling of the concrete cover. Other consequences of this process were condensation/funguses (6) (Figure 21, right), but these were less frequent (detected in 43 per cent of the cases) as they require more permanent damp conditions.

Cracking of external coatings (3) (Figure 22, left) and humidity/peeling in external coatings (5) (Figure 22, right) occurred in all but one of the arenas. The exceptions were very recently maintained spaces. These are anomalies to be expected in any outdoor facility exposed to rain, wind and solar radiation in which the external coatings' natural ageing and some deficiencies in terms of drainage design are bound to lead to cracking and peeling of the outer paints and even mortars. This is true both for the recent and the ancient bullfighting arenas.
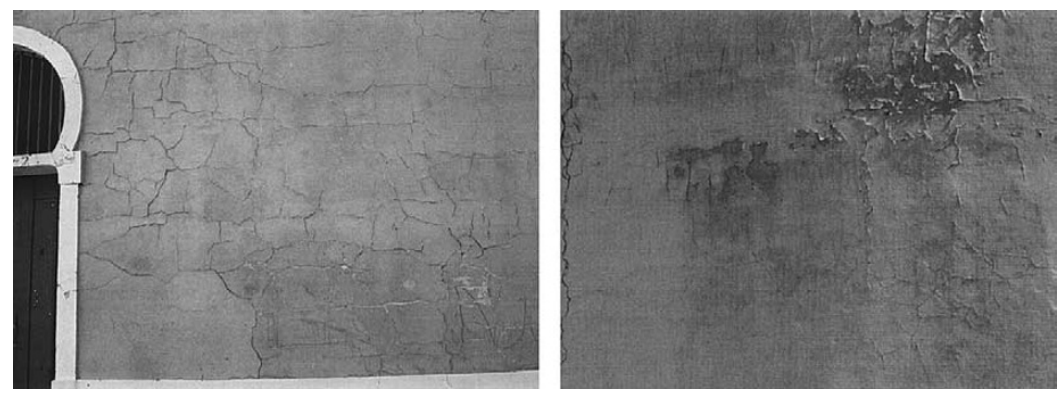

Figure 22: Cracking (left) and humidity/peeling (right) of external coatings in Salvaterra de Magos 


\section{Analysis of the defects' frequency}

Table 3: Nonstructural pathologies detected in the structural assessment of the bullfighting arenas

\begin{tabular}{lc}
\hline Description & Frequency (\%) \\
\hline I Drainage system deficiencies & 100 \\
2 Vandalism & 43 \\
3 Railing deterioration & 29 \\
\hline
\end{tabular}

\section{Nonstructural pathologies}

During the structural assessment of the bullfighting arenas, some nonstructural pathologies were registered, such as deficiencies in the drainage system. In Table 3 the frequency and variety of the main pathologies of this type are presented.

An analysis of Table 3 leads to the conclusion that there were deficiencies in the drainage system (1) (Figure 23) in all the bullfighting arenas assessed. These deficiencies were associated with insufficient slopes of the drains/benches, leading to water stagnation, clogging or deterioration of the drainage pipes, or even, in some cases, their nonexistence. In the case of the roofing of the cabins, the water would drain around the tops of the slabs/shells because there were no drains at all or because the holes serving as drains had no projecting pipes (Figure 23, right). It must be pointed out that this pathology, together with the lack of waterproofing in benches and roofing, was directly related to most of the structural or construction pathologies described above, as well as to most of the durability pathologies.

The two other nonstructural pathologies detected, vandalism (2) (Figure 24, left) and railing deterioration (3) (Figure 24, right), were less frequent (43 and 29 per cent of the cases, respectively). This is the type of problem that the body for inspecting entertainment activities/facilities is more focused on and therefore these were eliminated more frequently by the arenas' owners through maintenance. Usually, when the metallic railings were considered unsafe, the seats nearby were closed to the public. As for vandalism, it is a social phenomenon common in today's society and it affects every public or private property independently of its architectural/cultural/historical importance. Due to lack of funds, some
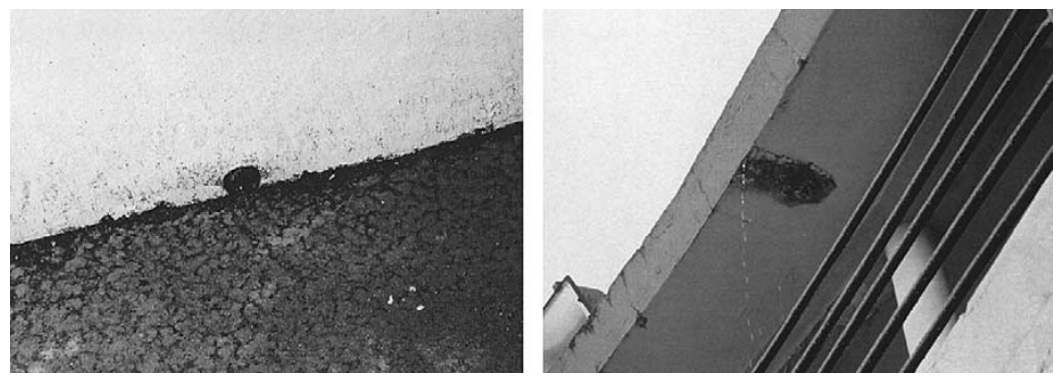

Figure 23: Drainage system deficiencies in the benches at Alter do Chão (left) and in the concrete roofing in Abiúl (right) 

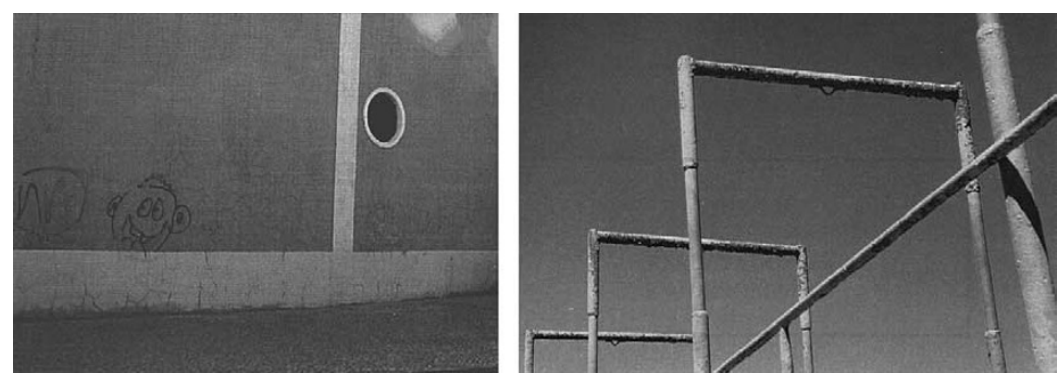

Figure 24: Vandalism in Salvaterra de Magos (left) and railing deterioration in Amareleja (right)
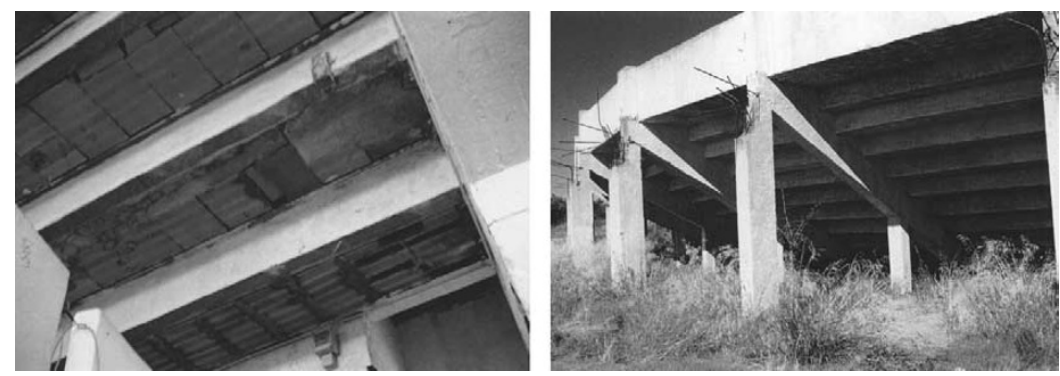

Figure 25: Mortar patches inside hollow bricks from the seats in Montijo (left) and exposed concrete superstructure in Elvas (right)

rehabilitation works had been very poorly done (Figure 25, left) with displeasing aesthetic results.

\section{REHABILITATION RECOMMENDATIONS}

For each arena, a set of recommendations was made concerning the elimination of the causes of each type of anomaly detected, wherever possible, and the rehabilitation of the anomaly itself, when deemed necessary. A summary of these recommendations in terms of type of anomaly is presented next.

\section{Structural or construction pathologies}

As seen in Table 1, most of the major structural problems detected (anomalies 3, 4, 5, 6, 8, 10 and 11 and anomaly 3 from Table 2) concerned the concrete structural elements (the rehabilitation of the most frequent anomaly, number 1, infiltration of various origins, will be described later with the durability pathologies). In one case, the urgency and potential danger involved were such that the arena was temporarily closed down. The following measures were proposed:

- cracking of concrete elements, in almost every case, was accompanied by corrosion of their reinforcement (anomaly 3 in Table 2) and often by spalling of the concrete cover. The standard treatment in these cases is the removal of any loose/delaminated concrete (as well as inadequate patching from previous repair work), sandblasting of the rebars to remove rust, elimination of loose concrete powder using compressed 


\section{Rehabilitation of elements other than those made of concrete}

air, replacement/lap splicing of the heavily corroded rebars and concreting with shrinkage-free mortar. The use of a protective coating such as an adequate paint (in most cases the concrete was exposed Figure 25, right - and in the ones in which it was not the paint/coating was not adequate for this purpose) was recommended; some very thin slabs with serious corrosion and spalling problems (eg in the bull pen areas) might have to be replaced altogether;

- in the case of the columns shown in Figure 13 (BA7), a special procedure was proposed: the cabins' roofing was to be shored next to the columns, all the loose concrete and corrosion products were to be removed, a shrinkage-free epoxy mortar was to be used to reconstruct the column node, a monitoring system was to be implemented to make sure the cracking would not happen again, otherwise, the columns were to be strengthened and measures taken to stop the wall settlement and decrease the effects of the movements of the roofing;

- porous concrete was to be injected with an epoxy shrinkage-free mortar after removal of all loose particles; in a couple of cases of beams and columns, the quality of the concrete was too low (inadequate materials and poor workmanship) to guarantee structural safety and it was proposed that the elements affected should be demolished and rebuilt, as strengthening is more costly and the conservation of these modern concrete additions was not important;

- columns with a lack of verticality did not pose a serious problem and no measures were proposed;

- gaping expansion joints were to be subject to standard procedures, which included removal of all degraded materials, remaking of concrete edges, replacement of sealants and drainage design.

Although they are outside the scope of this paper, the following measures were proposed for the structural anomalies concerning the masonry superstructure (anomalies 12 and 13 in Table 1):

- cracked walls were to be injected with a lime and cement mortar; measuring devices bridging both sides of the most important cracks were to be monitored; if cracking resumed, the foundations of the walls would need to be strengthened in order to stop further settlement;

- loose or missing bricks and stones from the arches or vaults were to be repositioned using adequate mortar.

Degraded timber elements (anomaly 14) in the seats of part of the Abiúl arena were to be replaced as they were beyond repair and other materials that would be easier to maintain and more durable used. As for cracking of nonstructural, hollow-brick walls (anomaly 7), it was a minor problem which could be solved by removing the mortar next to the cracks, removing loose particles, injecting the cracks, placing a glass-fibre grid over them and replacing the mortar and paint removed. If cracking resumed, the foundations of the walls would have to be strengthened by 
increasing their width. All these anomalies are common to other types of construction and their rehabilitation was therefore standard.

Finally, the three structural problems concerning the benches were to be solved by injecting the cracks at the supports with an elastomeric mortar (anomaly 2 in Table 1), removing the mortar patches, filling the broken voids of the bricks with a lightweight aggregate mortar (anomaly 9) and replacing the over-deformed timber benches (anomaly 15) with a more durable material. Where the benches were made of hollow bricks, sometimes even with an inserted steel bar, the deteriorated bricks or rebars were to be replaced.

\section{Durability pathologies}

The major durability-related problems were the lack of waterproofing membrane in the benches/roofing (anomaly 1 in Table 2), water dribbling with signs of rust and salts (anomaly 2 in Table 2), which was mostly caused by the previous problem, water infiltration from the benches (anomaly 1 in Table 1), and finally reinforcement corrosion (anomaly 3 in Table 2), which has been dealt with above. Therefore, in all the arenas, it was proposed that some kind of waterproofing system should be introduced in the benches. The solution needed to be adapted in terms of the materials of the benches, their overcoat and support for each case. In some cases, the best that could be done was to widen all the visible cracks in the benches, overcoat and inject them with an adequate material. In others, a liquid waterproofing system could be used to coat all the benches, while in yet others, the benches' facing could be removed in order to apply a membrane before repositioning the facing. In concrete roofings, the latter solution was recommended. This would automatically solve the water infiltration problems, provided the drainage problems (see below) were also addressed.

Problems with the external coatings of walls, seats and soffits of vaults (anomalies 4, 5 and 6 in Table 2) were detected and fall within the nonstructural common rehabilitation field. Thus, degraded coatings (either lime or cement-based mortars) needed to be assessed in each case to decide between total replacement with a similar material (removing all previously peeled, loose or infected material and allowing the remaining mortar/background to dry) or local repair:

\section{Rehabilitation of ancient structures}

- in the case of fungus growth, they must be removed with an adequate product (usually a mild leaching solution);

- for localised cracks, they needed to be widened and filled with shrinkage-free lime and/or cement mortars (compatible with the preexisting mortars);

- peeled paint needed to be removed and the area repainted;

- whenever the coatings or their backgrounds were humid, they must be allowed to dry before any repair was performed (eg by repairing at the end of the summer);

- regular maintenance of the coatings must be implemented, including painting or whitewashing at regular intervals, especially for the outer surfaces. 


\section{Nonstructural pathologies}

The main nonstructural pathology, drainage system deficiencies (anomaly 1 in Table 3 ), needed to be dealt with simultaneously to the waterproofing system of the benches and roofing, in order to prevent further occurrences of water infiltration to the elements below. Potential ponding locations were to be eliminated, drains needed to be created or have their slope increased, drain pipes needed to be created, lengthened or widened (especially in flat or almost flat confined spaces) and connected to the public drainage system. Regular maintenance in the shape of vegetation and debris removal from the drains and pipes of the system was absolutely essential to keep it functional. The drainage of roofings needed to be checked and corrected to stop water infiltration and drainage over the tops.

Likewise, the elimination of deteriorated metallic railings (anomaly 3 ) and the results of vandalism/faulty rehabilitation works (anomaly 2) must be complemented with proper and timely maintenance. The operations involved, respectively, were as follows:

- sandblasting of the corrosion of the metallic railings and appliance of a proper corrosion treatment and painting; in some cases when the present railings were not safe, they were to be replaced with a more convenient solution or strengthened with diagonal struts;

- unsightly graffiti and mortar patches were to be painted over.

\section{Sclerometer testing}

\section{CONCRETE STRENGTH CAMPAIGN}

\section{Description of the test, its range and validity}

In all the seven bullfighting arenas a sclerometer campaign was implemented. This is a nondestructive in situ test that allows the estimation of the resistance of the superficial concrete. It is based on an empirical relationship established between the hardness of the concrete and its resistance, in which the rebound of a calibrated mass, compressed against the concrete surface through a spring that is afterwards released, is measured. The displacement of the mass indicates the sclerometric factor $\mathrm{N}$, related to the average compression resistance of the concrete $f_{c m}$.

The results of this test are influenced by a number of parameters that include the types of cement and aggregates, the humidity, surface irregularities, surface carbonation, etc. Consequently, the test must be used with some caution and at least ten measurements taken for each testing site. The test is indicated mostly for comparative studies of concrete in several different areas of the same structure.

As the number of sites analysed in each arena was not, in general, sufficient to validate statistically the conclusions of a numerical nature presented below, these must be accepted with some reservations. Nevertheless, they allow an understanding of a number of trends that are useful to predict the structural behaviour of these infrastructures. 


\section{Results analysis}

One of the most striking features of this campaign was the lack of data concerning the construction and refurbishment of these arenas. Indeed, there was no written register of the construction of the oldest pre-concrete structures (BA1 and BA2) or the concrete additions they were subjected to in the many decades since. If this was somehow to be expected, as these arenas were about 100 years old, the fact that in the other arenas there was either no project plan at all or it was unavailable (even to the owners and/or authorities) was a bit of a surprise. In at least two of the arenas (BA4 and BA5), the initiative to build them came from an ad hoc popular commission that somehow raised part of the money necessary and started to build with no design plans, merely based on the contractors' experience.

The result was that, of the arenas inspected, none had design plans during the structural assessment, only three (BA3, BA6 and BA7) had concrete superstructure built in a single phase, in three others (BA1, BA4 and BA5) it was done in two stages (at least) and in another (BA2) three stages were identified (based on verbal statements from past caretakers). Therefore, it was not possible to know which concrete compression strength classes were previewed for the different structural elements in the arenas.

The in situ results, with all the reservations presented above and for a variation coefficient $\delta$ considered to be equal to 15 per cent (a value recommended in most references on the subject for current concretes), indicate, in most cases, an adequate strength class (to be expected in reasonably well-built structures):

\section{Concrete strength results}

- in columns, in general from $C 20 / 25$ to $C 25 / 30$ and even more (C30/37 in BA6);

- in beams, the results varied between C20/25 and C30/37 (in BA1);

- in slabs, only two results were gathered: C20/25 (in BA2) and C30/37 (in BA1);

- in seats, only one arena (BA2) was analysed: C25/30.

These results generally present an acceptable heterogeneity (for each structural element type and within the same arena there were no strength classes further than one class apart), thus indicating reasonable quality control. But the two arenas mentioned above as being built with hardly any control from the authorities - BA4 and BA5 - showed very different results. In both cases, it was possible to identify two different construction stages. In BA4, only the second stage elements were tested (the first stage's apparent quality was even worse than the second) and the compression strength results were below the minimum structural concrete class according to Eurocode 2 at C12/15. This structure was definitely substandard independently of the loads to which it was subjected. In BA5, structural elements of both stages were tested. The second stage, showing a better quality, presented results similar to those of the other arenas summarised above. The first stage columns were recorded as C16/20 and 


\section{Phenolphthalein testing}

\section{Carbonation depth results}

\section{Linear correlations}

the beams ranged from C13/15 to C20/25. Even though probably substandard, this structure was not as worrisome as BA4.

It was thus verified that the few situations of nonconformity and higher scatter tended to occur more in the lower strength classes, associated with less execution and quality control and deficient/nonexistent design plans. The results presented here show the usefulness of this test for the assessment campaign.

\section{CARBONATION MEASUREMENTS}

\section{Description of the test}

The determination of the carbonation front depth was made by using a spray with a phenolphthalein solution, which changes colour (from dark rose to colourless) and thus indicated the concrete areas with a $\mathrm{pH}$ below 9 , which was the region where the natural alkalinity of the concrete had been neutralised. This situation, when combined with oxygen and humidity in large enough quantities, may lead to the initiation of reinforcement corrosion.

Measurements were performed at the bullfighting arenas (except for BA7) in holes made with a $25 \mathrm{~mm}$-diameter drill. The length of the holes was increased gradually from the surface in order to identify the interface between the carbonated region and the noncarbonated region, ie the carbonation front. The depth of carbonation was measured with a calliper rule with a device at its end to facilitate the visualisation of the reference position of the concrete surface.

\section{Results analysis}

During these tests, the values of the carbonation front depth were registered both in linear structural elements (columns and beams) and in plane elements (slabs and seats). As the age of the assessed concrete structural elements varied, for each value registered a proportionality coefficient between the carbonation depth (d) and the square root of time $(\mathrm{t})$, from here on called the carbonation coefficient $(\mathrm{d}=\mathrm{C} \sqrt{\mathrm{t}})$, was determined. Figures 26 and 27, concerning cast in situ elements both exposed and coated (usually with paint), present the variation of the carbonation coefficient with the average compression strength of the concrete $\left(f_{\mathrm{cm}}\right)$, evaluated by using a sclerometer.

The first conclusion that can be drawn from these diagrams is the very high scatter of the results, expressed in the low values of $\mathrm{R}^{2}$ in both the linear regressions (especially for the coated elements). This situation can be explained by various factors. First, variability of results is normally associated with the use of the sclerometer, which is a test more appropriate for comparative analyses of different concrete areas than for the determination of the absolute value of their respective compression strengths. Secondly, the phenolphthalein test performed in situ is subject to some imprecision, more so because the depth of the carbonation front undergoes variations associated with local effects such as the existence of coarse aggregates. Thirdly, the small number of carbonation tests performed (especially for the coated elements). Fourthly, the variability of 


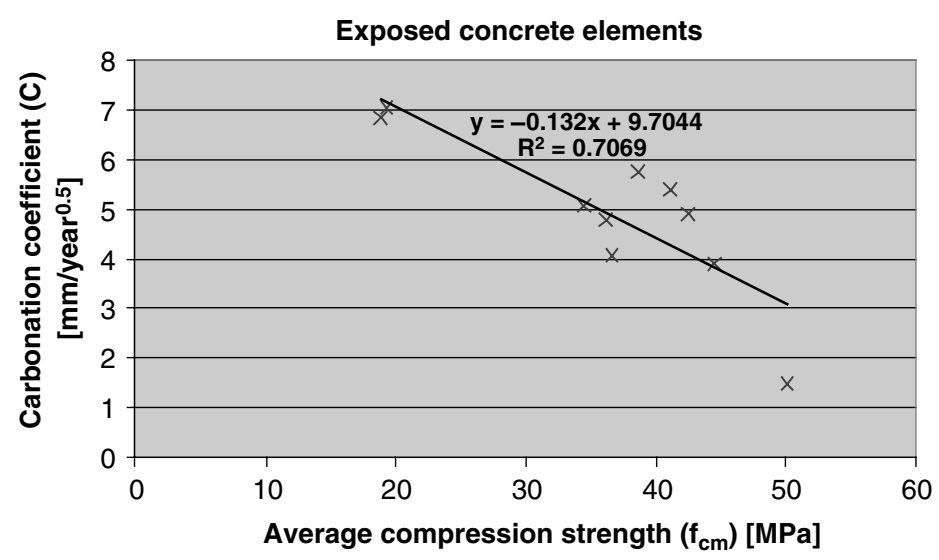

Figure 26: Carbonation coefficient (C) versus concrete average compression strength $\left(f_{\mathrm{cm}}\right)$ for exposed cast in situ elements

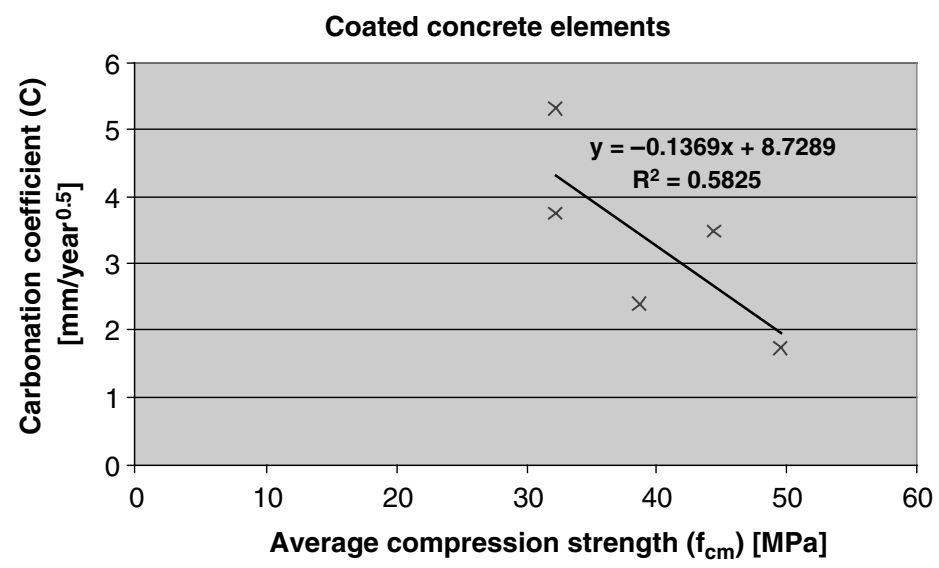

Figure 27: Carbonation coefficient $(C)$ versus concrete average compression strength $\left(f_{\mathrm{cm}}\right)$ for coated cast in situ elements

natural phenomena, which are generally more complex than the theoretical models that aim at predicting them. Nonetheless, it seems obvious from these results that the compression strength of the concrete, just by itself, is not enough to make a solid prediction of the rate of penetration of the carbonation front, ie other factors need to be taken into account, such as the quality of the workmanship during concrete casting and compaction and the natural aggressiveness of the environment. Local effects in terms of concrete porosity and humidity penetration may also play an important role.

Based on the diagrams presented in Figures 26 and 27, it can be concluded that, both for the exposed and the coated cast in situ elements, the values of the carbonation coefficient $(\mathrm{C})$ decrease as the average compression strength increases.

The effect of coating

Again through an analysis of the diagrams, the favourable effect of the coating of the elements can be confirmed, meaning that for equal values of the compression strength the carbonation coefficient was greater for the exposed elements. This effect is felt through the whole range of 
compression strength values in terms of the linear regression equation but in real situations (eg comparing an exposed element with a painted element in the same arena) the difference was not always as pronounced. Furthermore, some of these results should be looked at with some caution as in some cases there were no data concerning the actual age of the painting as compared with the total age of the painted element.

\section{CONCLUSIONS (CONCERNING THE CONCRETE BULLFIGHTING ARENAS)}

This paper presents the main pathologies detected during a structural assessment campaign performed on seven concrete bullfighting arenas in various regions of Portugal, the structural type and construction materials of which have been described previously. A summary of the recommendations for rehabilitation of the arenas has been provided. The paper also presented relationships between the depth of the carbonation front and the concrete average compression strength (as estimated with a sclerometer), registered both in exposed and coated cast in situ concrete elements. Various main conclusions can be drawn from these assessments and they have been organised into four groups below.

\section{In terms of the pathologies found}

- these structures, being extremely exposed to the aggressiveness of the environment, were subject to extremely fast degradation mechanisms and might exhibit important problems even only a short period after construction;

- notwithstanding the fact that the concrete structures of these arenas were on average 35 years old and there had been virtually no maintenance during the whole period (with very few exceptions), the structural status of most of them was acceptable, and in only one case was it necessary to restrict their use temporarily;

- the pathologies can be grouped as structural, durability-related and nonstructural and they were interrelated;

- the most frequent structural pathologies were cracking in various elements and water-related problems; the most serious ones involved the widespread spalling of the lower concrete cover of the seats (due to corrosion) in one arena, several heavily damaged columns near the top (caused by slab and wall deformations) in another arena, and another arena, even though not presenting serious structural problems, was proved to have a low-standard concrete in terms of compression strength;

- concrete, as a structural material, was found to be not so durable (mostly due to the reinforcement within) as compared with masonry but better than metals, timber and mortars; however, with proper maintenance, the performance of all these materials, even the latter, would have been totally satisfactory;

- water-related problems, namely those caused by inefficiency/ nonexistence of waterproofing and drainage systems, practically monopolised the durability and nonstructural pathologies. 


\section{In terms of rehabilitation recommendations}

- for structures this old and with their extremely low level of maintenance, it was remarkable that so little strengthening was unequivocally proved to be needed;

- before any but the most urgent structural rehabilitation was performed, it would be necessary to solve the waterproofing and drainage problems of the benches and roofing;

- most of the remaining rehabilitation concerned the treatment of structural or nonstructural cracking and the external coatings, by resorting to conventional techniques.

\section{In terms of service life prediction}

- the prediction of the initiation period of corrosion of the reinforcement within concrete when associated with the carbonation process is a complex matter that cannot be oversimplified;

- correlations between the depth of the carbonation front and concrete compression strength are insufficient for this purpose as they exhibit very high scatter; nevertheless, the carbonation process tends to slow down as the concrete strength increases;

- in order to obtain better correlations, other factors besides concrete strength must be taken into account;

- the coating of concrete elements and the quality of their casting and compaction, as well as localised porosity and humidity, significantly influence these correlations.

\section{In terms of design rules for bullfighting arenas}

- the benches and cabins' roofing at bullfighting arenas are subjected to extremely rough environmental conditions;

- as water penetration is the starting point of the great majority of the potential problems, the benches and cabins' roofing must always be waterproofed, the expansion joints must be adequately designed and maintained and the drainage system must be impeccable (in terms of slopes, drain capacity, positioning and materials, preventing water from flowing over concrete surfaces and maintenance);

- standard paints provide some protection to exposed elements but this trend is not consistent; in order to obtain a really effective protection, properly designed outer protections are needed;

- there is no effective maintenance-free design for very exposed concrete structures; they need to be taken care of throughout their service life on a periodical basis.

Expressway bridges, deck parkings and bullfighting arenas

\section{BENCHMARKING BETWEEN EXPOSED CONCRETE} STRUCTURES

The present paper is the third in a series detailing inspection campaigns concerning exposed concrete structures: expressway bridges (de Brito 


\section{Most frequent structural anomalies in all types of structure}

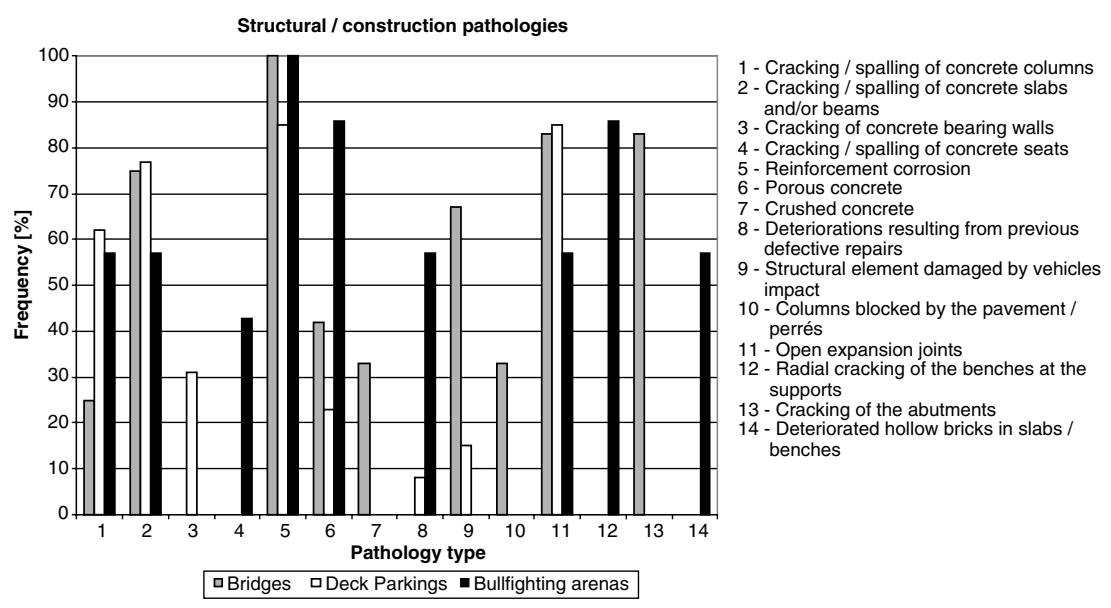

Figure 28: Benchmarking between bridges, deck parkings and bullfighting arenas in terms of structural or construction pathologies

et al. (2005a), deck parkings in commercial malls (de Brito et al. (2005b) and bullfighting arenas (which can be representative of stadia). The fact that they share certain similarities (the main structural material, the very harsh aggressive environment to which they are subjected, the lack of protection measures and a relative deficiency in terms of maintenance) justifies a benchmarking study, to try to understand common trends of pathology that may lead to efficient prevention/maintenance/rehabilitation measures.

The benchmarking study used the same groups of anomalies as listed in the present paper: structural or construction pathologies, durability pathologies and nonstructural pathologies. For comparison purposes, some adjustments were made in terms of classification and denomination of some of the anomalies. In Figure 28, the frequency of the structural or construction pathologies that occurred in at least 30 per cent of one of the types of structure is presented. From an analysis of Figure 28, it can be concluded that there are some anomalies that are prevalent in every type of structure:

- cracking/spalling of concrete columns (1);

- cracking/spalling of concrete slabs and/or beams (2);

- reinforcement corrosion (5);

- porous concrete (6);

- open expansion joints (11).

All these anomalies are connected with the reinforcement corrosion mechanism (detected in almost every case in all structures), with anomalies 6 and 12 being the causes and the others the consequences. This mechanism may be considered inevitable for this type of structure and the only measures that can be taken aim at slowing down the process: adequate vibration of the concrete, adequate design and maintenance of the expansion joints, use of a protective paint periodically applied and light repair whenever cracking or spalling is detected. 
Most frequent

structural anomalies for each type of structure

\section{Most frequent durability anomalies in all types of structure}

In Figure 28 a number of sometimes very frequent anomalies stand out as specific to each type of structure:

- cracking of concrete bearing walls (3) in deck parkings;

- cracking/spalling of concrete seats (4) in bullfighting arenas;

- crushed concrete (7) in bridges;

- deterioration resulting from previous defective repairs (8), mostly in bullfighting arenas;

- structural element damaged by vehicle impact (9), mostly in bridges;

- columns blocked by the pavement/perrés (10) in bridges;

- radial cracking of the benches at the supports (12) in bullfighting arenas;

- cracking of the abutments (13) in bridges;

- deteriorated hollow bricks in slabs/benches (14) in bullfighting arenas.

In Figure 29, the frequency of the durability pathologies that occurred in at least 30 per cent of one of the types of structure is presented. From an analysis of Figure 29, it can be concluded that there are some anomalies that are prevalent in every type of structure:

- infiltration of various origins (1);

- drainage over structural elements with signs of rust and salts (2);

- lack of waterproofing membrane in deck/benches/roofing/exposed pavement (3).

Once again, these anomalies are different perspectives of the same phenomenon popularly stated as 'water is the worst enemy of a construction', which is never truer than for structures as exposed to such environmental aggression as these. Anomaly 3 in the deck of bridges, in the exposed pavement of deck parkings or in the benches or roofing of bullfighting arenas, together with a nonstructural anomaly cited below (drainage system facilities), are the causes of water penetrating within

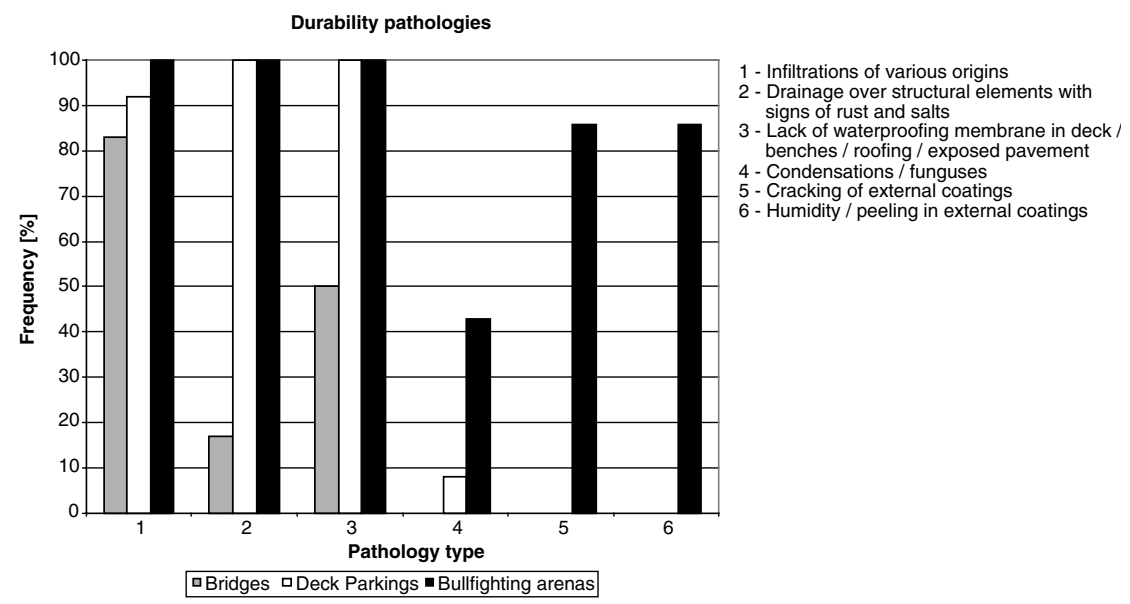

Figure 29: Benchmarking between bridges, deck parkings and bullfighting arenas in terms of durability pathologies 


\section{Most frequent durability anomalies for each type of structure}

\section{Most frequent nonstructural anomalies in all types of structure}

the structure and causing diverse anomalies, both nonstructural (salts deposition, biological growth, etc) and structural (reinforcement corrosion and all the related problems). The watertightness of concrete structures and those of any other material is essential to ensure their durability. The very high frequency with which all these anomalies occur in every type of structure within the benchmarking must be stressed.

In Figure 29 a few, in most cases very frequent, anomalies stand out as specific to bullfighting arenas, occurring mostly in external coatings, and clearly a durability liability:

- condensations/funguses (4);

- cracking of external coatings (5);

- humidity/peeling in external coatings (6).

In Figure 30, the frequency of the nonstructural pathologies that occurred in at least 30 per cent of one of the types of structure is presented. From an analysis of Figure 30, it can be concluded that some anomalies are prevalent in every type of structure (where they are feasible):

- drainage system deficiencies (1);

- lighting system deficiencies (2);

- railing deterioration/nonexistence (3);

- cracking of nonstructural walls (4);

- vandalism (5).

Contrary to the other groups of pathologies, the anomalies common to all the types of structure are one of each origin: the drainage system is by far the most frequent and, as stated before, is at the root of many widespread problems; the lighting system deficiencies have no other consequence than the endangerment of users and vehicles (in bridges); the inadequacy of the railings is mostly connected with their corrosion and lack of maintenance and sometimes presents a very worrying safety problem;

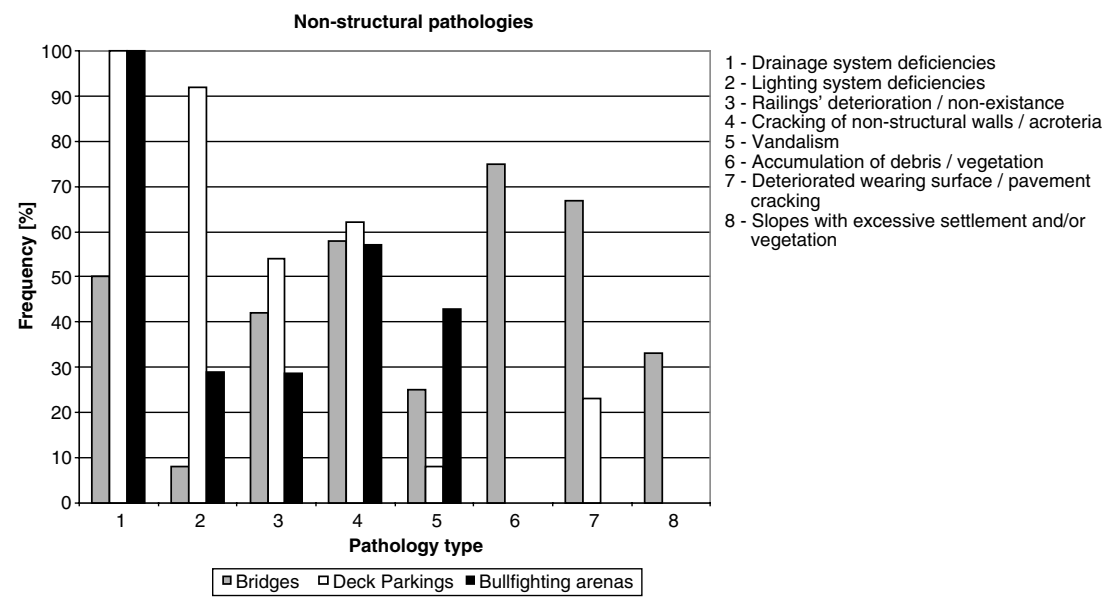

Figure 30: Benchmarking between bridges, deck parkings and bullfighting arenas in terms of nonstructural pathologies 


\section{Most frequent nonstructural anomalies for each type of structure}

cracking of nonstructural walls is mostly due to foundations settlement or vehicle impacts (in the case of the acroteria of bridges); finally, vandalism is a common trend in every structure nowadays.

In Figure 30 some rather frequent anomalies stand out as specific mostly to bridges, occurring fundamentally because of lack of maintenance:

- accumulation of debris/vegetation (6) in bridges;

- deteriorated or wearing surface/pavement cracking (7);

- slopes with excessive settlement and/or vegetation (8).

As a summation of this benchmarking, it can be said that every exposed concrete structure is especially subject to corrosion reinforcement, especially if watertightness and periodic maintenance are not guaranteed.

\section{Acknowledgments}

This contribution has been prepared based on a number of reports developed within ICIST/IST by the authors, at the request of the Portuguese Cultural Activities General Inspection Body, IGAC.

\section{References}

de Brito, J., Branco, F.A. and Santos, J.R. (2005a) 'Analysing the defects of the Lisbon Ring Expressway bridges', Journal of Building Appraisal, 1(2), 177-189.

de Brito, J., Branco, F.A., Santos, J.R. and Paulo, P. (2005b) 'Characterisation of current defects in deck parkings', Journal of Building Appraisal, 1(3), 253-267.

de Brito, J. and Branco, F. (2006) 'Structural assessment of ancient bullfighting arenas', Construction and Building Materials, under revision. 